\title{
Studi Optimasi Reposisi Recloser Untuk Meningkatkan Keandalan Pada Penyulang Blahkiuh Menggunakan Metode Algoritma Genetika
}

\author{
I Ketut Ariek Astana Adi ${ }^{1}$, I Gede Dyana Arjana ${ }^{2}$, Widyadi Setiawan ${ }^{3}$ \\ Program Studi Teknik Elektro, Fakultas Teknik, Universitas Udayana \\ Email: astanaarik@gmail.com ${ }^{1}, \underline{\text { dyanaarjana@unud.ac.id }}{ }^{2}, \underline{\text { widyadi@unud.ac.id }}^{3}$
}

\begin{abstract}
Abstrak
Keandalan pada dasarnya merupakan kemampuan suatu peralatan atau komponen dalam menjalankan fungsinya dengan baik pada suatu sistem dalam kondisi operasi tertentu. Indeks keandalan penyulang Blahkiuh berdasarkan penelitian tahun 2016 adalah SAIDI 35,894 jam/pelanggan/tahun dan SAIFI 16,534 kali/pelanggan/tahun. Keandalan suatu penyulang harus perlu ditingkatkan guna menunjang tujuan PT. PLN (Persero) mencapai WCS dan WCC yaitu dengan indeks keandalan SAIDI 100 menit/pelanggan/tahun dan SAIFI 3 kali/pelanggan/tahun. Salah satu cara yang dapat dipakai yaitu dengan mereposisi recloser saluran ke tempat yang lebih tepat dengan mempertimbangkan jumlah pelanggan dan panjang saluran penyulang tersebut. Algoritma Genetika digunakan untuk mendapatkan letak reposisi recloser yang optimal yaitu pada load point-load point yang sudah ditentukan dengan meminimalkan indeks keandalan berupa nilai SAIDI dan SAIFI. Metode ini dapat mudah diimplementasikan dalam berbagai persoalan pengoptimasian karena memberikan solusi yang lebih baik di setiap iterasinya. Dengan menggunakan metode algoritma genetika, didapatkan nilai fitness tertinggi mencapai 0,560 dengan letak recloser yang paling optimal yaitu di load point 11, 21, 48, 78 serta nilai SAIDI 0,919 jam/pelanggan/tahun dan SAIFI 0,864 kali/pelanggan/tahun. Bila dibandingkan dengan penelitian tahun 2016 maka dengan menggunakan metode algoritma genetika didapatkan hasil keandalan berupa indeks SAIDI dan SAIFI yang sudah memenuhi standar WCS dan WCC.
\end{abstract}

Kata kunci : Keandalan, Algoritma Genetika, Recloser.

\section{PENDAHULUAN}

Gaya hidup masyarakat modern saat ini sangat dekat dengan teknologi. Perkembangan teknologi yang pesat menimbulkan sikap kritis konsumen terhadap kontinuitas suplai daya listrik. Untuk menjaga kontinuitas suplai daya ke konsumen tetap terlaksana dengan baik maka diperlukan sistem jaringan distribusi yang andal. Untuk meningkatkan keandalan sistem jaringan distribusi, pada saluran dapat dibagi menjadi beberapa section beban. Pembagian dilakukan dengan pemasangan recloser dan dibantu oleh LBS, sehingga apabila terjadi gangguan daerah yang padam dapat diminimalisir serta mempermudah dalam melakukan manuver.

System Average Interruption Duration Index (SAIDI) dan System Average Interruption Frequency Index (SAIFI) merupakan salah satu parameter keandalan dalam sistem jaringan distribusi tenaga listrik. Tingkat kualitas keandalan sistem jaringan distribusi dapat dihitung melalui perbandingan lama gangguan dengan jumlah nilai yang dipakai serta perbandingan jumlah total gangguan dengan jumlah konsumen yang dilayani. Keandalan yang baik akan menunjang tujuan PT. PLN (Persero) yaitu mencapai World Customer Service (WCS) dan World Class Company (WCC) yaitu dengan indeks keandalan SAIDI $=100$ menit/pelanggan/ tahun. Dan SAIFI $=3$ kali/pelanggan/tahun.

Penyulang Blahkiuh merupakan salah satu penyulang yang disuplai oleh Gardu Induk Kapal. Panjang total penyulang Blahkiuh yaitu 95,745 Kms. Terdapat 4 buah recloser pada penyulang Blahkiuh yaitu recloser ulapan, recloser Kembang Sari, recloser Kerta dan recloser Kiadan. Berdasarkan penelitian pada tahun 2016 
penyulang Blahkiuh memiliki nilai SAIDI sebesar 35,894 jam/pelanggan/tahun dan nilai SAIFI sebesar 16,534 kali/pelanggan/ tahun [1].

Penutup Balik Otomatis (Recloser) merupakan alat yang penting dalam menangani suatu gangguan. Jaringan distribusi listrik yang sedang mengalami gangguan distribusi dapat dinormalkan dan diperkecil daerah gangguannya dengan menggunakan recloser.

Dalam mengoptimasi penempatan recloser sudah dilakukan dengan banyak metode. Setiap metode memiliki kekurangan dan kelebihan sehingga belum tentu penggunaan suatu metode lebih baik dari metode lain. Metode yang dapat digunakan untuk melakukan optimasi adalah algoritma genetika. Metode algoritma genetika dapat memaksimalkan keandalan dengan cara menentukan posisi penambahan recloser yang tepat [2] dan menentukan panjang lintasan pada jaringan ad hoc [3]. Sehubungan dengan hal tersebut, maka peneliti dalam penelitian ini akan melakukan studi optimasi reposisi recloser saluran untuk meningkatkan keandalan sistem pada penyulang Blahkiuh menggunakan metode algoritma genetika.

\section{KAJIAN PUSTAKA}

\subsection{Keandalan Sistem Distribusi Tenaga Listrik}

Konsep keandalan aplikasi sistem distribusi berbeda dengan aplikasi sistem pembangkitan dan aplikasi sistem transmisi. Sistem distribusi lebih berorientasi pada titik beban pelanggan daripada wujud sistem. Sistem distribusi lokal lebih diperhitungkan daripada sistem terintegrasi secara luas dalam ruang lingkup fasilitas pembangkitan dan transmisi. Keandalan sistem pembangkitan dan transmisi lebih mempertimbangkan probabilitas hilangnya beban (loss of load), dengan lebih sedikit melihat komponen sistem, sedangkan keandalan distribusi melihat ke semua aspek dari teknik, seperti desain, perencanaan, pengoperasian. Sistem pembangkitan dan transmisi yang terintegrasi lebih kompleks dari sistem distribusi, sedangkan perhitungan probabilitas metematiknya lebih sederhana dibandingkan yang dibutuhkan untuk penaksiran keandalan pembangkitan dan transmisi [2].

\subsection{Indeks Keandalan}

Indeks keandalan yang dievaluasi menggunakan konsep klasik yaitu menghitung laju kegagalan rata-rata $(\lambda)$, durasi pemadaman rata-rata $(r)$, dan ketidaktersediaan tahunan rata-rata $(U)$. Indeks keandalan adalah suatu besaran probabilitas yang menyatakan indikator keandalan.

Keandalan dari pelayanan konsumen dapat dinyatakan dalam beberapa indeks yang biasanya digunakan untuk mengukur keandalan dari suatu sistem. Adapun indeks tersebut, antara lain:

1) System Average Interuption Duration Index dapat didefinisikan sebagai nilai rata-rata dari lamanya kegagalan untuk setiap konsumen selama satu tahun. Perhitungan dengan metode Section Technique dimulai dengan menghitung SAIDI per load point menggunakan persamaan berikut:

$$
\text { SAIDI }=\frac{\sum \mathrm{U}_{\mathrm{i}} \cdot \mathrm{N}_{\mathrm{i}}}{\sum \mathrm{N}_{\mathrm{i}}}
$$

Dimana:

$\mathrm{U}_{\mathrm{i}}=$ Ketidaktersediaan komponen (jam/tahun)

$\mathrm{N}_{\mathrm{i}}=$ Jumlah beban pada titik beban $i$ (pelanggan)

$\mathrm{N}=$ Jumlah total beban pada satu sistem (pelanggan)

2) System Average Interuption Frequency Index dapat didefinisikan sebagai jumlah rata-rata kegagalan yang terjadi per pelanggan yang dilayani oleh sistem per satuan waktu (umumnya per tahun). Perhitungan dengan metode Section Technique dimulai dengan menghitung SAIFI per load point menggunakan persamaan berikut :

$$
\text { SAIFI }=\frac{\sum \lambda_{\mathrm{i}} \cdot \mathrm{N}_{\mathrm{i}}}{\sum \mathrm{N}_{\mathrm{i}}}
$$

Dimana :

$\lambda_{\mathrm{i}}=$ Laju kegagalan (kegagalan/ tahun) 


$$
\begin{gathered}
\mathrm{N}_{\mathrm{i}}=\begin{array}{l}
\text { Jumlah beban pada titik beban } i \\
\text { (pelanggan) }
\end{array} \\
\mathrm{N}=\underset{\text { Jumlah total beban pada satu }}{\text { sistem (pelanggan) }}
\end{gathered}
$$

\subsection{Algoritma Genetika}

Algoritma genetika merupakan salah satu metode yang sangat tepat digunakan dalam menyelesaikan masalah optimasi kompleks, yang sulit dilakukan oleh metode konvensional. Metode algoritma genetika merupakan suatu metode pencarian yang berbasis pada mekanisme seleksi alam dan genetika [4].

\section{METODELOGI PENELITIAN}

Penelitian dilakukan di PT. PLN (Persero) Rayon Mengwi. Sumber data penelitian ini berupa data sekunder yang diperoleh dari PT. PLN (Persero) Rayon Mengwi, serta studi literatur. Jenis data yang digunakan dalam penyususan penelitian ini adalah data kuantitatif, yaitu data single line diagram, data panjang penyulang, dan jumlah pelanggan pada penyulang Blahkiuh dari PT. PLN (Persero) Rayon Mengwi. Alur proses penelitian menggunakan metode algoritma genetika sebagai berikut:

1. Mengumpulkan data panjang penyulang Blahkiuh yang berupa data one line diagram dan data jumlah pelanggan.

2. Membagi penyulang Blahkiuh menjadi 5 section berdasarkan letak recloser.

3. Mencari nilai laju kegagalan, waktu keluaran dan ketidaktersediaan tiap section.

4. Menghitung nilai SAIDI dan SAIFI penyulang Blahkiuh.

5. Membangkitkan populasi menggunakan input jumlah dan nilai load point dari penyulang Blahkiuh.

6. Mengevaluasi kromosom dengan menggunakan alat ukur yang dinamakan fitness. Fitness function yang digunakan untuk menyelesaikan reposisi recloser ini dapat dirumuskan sebagai berikut:

$$
f(x)=\frac{1}{\text { SAIDISAIFI }}
$$

7. Melakukan proses Linier Fitness Ranking untuk menghindari terjadinya konvergensi premature.

8. Pemilihan kromosom sebagai orang tua sebanyak 2 buah dengan metode seleksi roulette whell.

9. Proses crossover (pindah silang) untuk memindah silangkan kromosom bapak dan kromosom ibu.

10. Melakukan mutasi terhadap semua gen yang terdapat pada individu.

11. Menentukan reposisi recloser dengan memilih nilai fitness terbaik.

12. Membandingkan keandalan sistem sebelum dan sesudah recloser direposisi.

\section{HASIL DAN PEMBAHASAN}

Penyulang Blahkiuh merupakan penyulang yang sistem kelistrikannya disuplai oleh Gardu Induk Kapal yaitu trafo III dengan kapastitas 60 MVA. Penyulang ini memiliki jumlah trafo distribusi sebanyak 94 buah. Total daya yang terpasang pada penyulang ini yaitu sebesar $7.120 \mathrm{kVA}$. Panjang saluran penyulang Blahkiuh yakni $95,745 \mathrm{Kms}$ dengan jaringan tipe radial. Total jumlah pelanggan (konsumen) pada penyulang Blahkiuh mencapai 11.045. Ada beberapa peralatan pengaman yang terpasang pada penyulang Blahkiuh antara lain LBS (Load Break Switch), AVS (Automatic Vacuum Switch) dan recloser. Terdapat 4 buah recloser yang terpasang pada penyulang Blahkiuh antara lain recloser ulapan, recloser kerta, recloser kembang sari dan recloser kiadan Berdasarkan penelitian yang diperoleh pada tahun 2016 penyulang Blahkiuh memiliki nilai indeks keandalan berupa SAIDI sebesar 35,894 jam/pelanggan/tahun dan SAIFI sebesar 16,534 kali/pelanggan/tahun [1].

Posisi peralatan atau komponenkomponen yang terpasang pada suatu penyulang dapat dipahami dengan melihat single line diagram penyulang tersebut. Single line diagram juga digunakan untuk mencari nilai ketidaktersediaan serta nilai laju kegagalan yang juga akan menjadi 
acuan dalam menghitung nilai SAIDI dan SAIFI. Data panjang saluran digunakan untuk mendapatkan nilai ketidaktersediaan dan nilai laju kegagalan yang akan dijadikan acuan untuk menghitung nilai SAIDI dan SAIFI. Panjang saluran penyulang Blahkiuh yaitu 95,745 Kms dengan jaringan tipe radial. Penyulang Blahkiuh memiliki jumlah pelanggan mencapai 11.045 yang tersebar di wilayah Badung dengan kategori umum. Data pelanggan digunakan untuk mencari nilai ketidaktersediaan dan nilai laju kegagalan yang nantinya juga digunakan acuan dalam menghitung nilai SAIDI dan SAIFI.

Penyulang Blahkiuh yang menggunakan konfigurasi sistem radial dibagi menjadi 5 section untuk mempermudah dalam proses perhitungan. Pembagian dilakukan berdasarkan dari letak recloser saluran pada penyulang Blahkiuh. Dalam perhitungan keandalan masing-masing peralatan dapat dianalisa secara terpisah karena kegagalan peralatan diasumsikan tidak saling berhubungan. Langkah awal yang dilakukan dalam menghitung keandalan yaitu mengetahui terlebih dahulu panjang saluran serta jumlah pelanggan dari penyulang Blahkiuh. Selanjutnya yaitu mulai menghitung nilai laju kegagalan atau failure rate $(\lambda)$ dan ketidaktersediaan $(U)$ peralatan atau komponen section 1 yang nantinya akan digunakan sebagai nilai keandalan pada section tersebut. Berdasarkan (SPLN) No. 59 Tahun 1985 diketahui indeks kegagalan sistem distribusi dapat dilihat pada Tabel 1 dan Tabel 2 .

Tabel 1. $\lambda$ dan $r$ Peralatan berdasarkan SPLN : 1985 [5]

\begin{tabular}{ccc}
\hline Peralatan & Failure rate $(\boldsymbol{\lambda})$ & $\begin{array}{c}\text { Repair } \\
\text { time }(\boldsymbol{r})\end{array}$ \\
\hline Sectionalizer & $0,003 /$ unit/tahun & $10 \mathrm{jam}$ \\
\hline Circuit Breaker & $0,004 /$ unit/tahun & $10 \mathrm{jam}$ \\
\hline Trafo distribusi & $0,005 /$ unit/tahun & $10 \mathrm{jam}$ \\
\hline
\end{tabular}

Tabel 2. $\lambda$ dan $r$ SUTM berdasarkan SPLN $: 1985$ [5]

\begin{tabular}{ccc}
\hline $\begin{array}{c}\text { Repair } \\
\text { time }\end{array}$ & $\begin{array}{c}\text { Sustained } \\
\text { failure rate } \\
(\lambda / \mathrm{km} / \mathrm{tahun})\end{array}$ & $\begin{array}{c}\text { Momentary } \\
\text { failure rate } \\
(\mathrm{\lambda} / \mathrm{km} / \mathrm{tahun})\end{array}$ \\
\hline
\end{tabular}

3 jam $\quad 0,2 \quad 0,003$

Nilai laju kegagalan atau failure rate $(\lambda)$ tiap peralatan dan nilai waktu perbaikan atau repair time ( $r$ ) tiap peralatan didapatkan berdasarkan acuan dari (SPLN) No. 59 Tahun 1985. Nilai laju kegagalan $(\lambda)$ didapatkan berdasarkan perkalian antara laju kegagalan tiap peralatan dengan panjang dari penyulang Blahkiuh. Nilai ketidaktersediaan $(U)$ didapatkan dengan mengalikan laju kegagalan $(\lambda)$ dan waktu perbaikan ( $r)$ tiap peralatan. Maka kemudian dilakukan perhitungan yang sama untuk mendapatkan nilai $(\lambda)$ dan $(U)$ tiap titik beban pada setiap section.

Untuk mendapatkan nilai SAIDI dan SAIFI tiap load point pada section 1 maka hasil dari failure rate atau laju kegagalan $(\lambda)$ dan ketidaktersediaan $(U)$ masing - masing dikalikan dengan jumlah pelanggan tiap load point pada section 1 didapatkan total nilai dari $(\lambda) \times$ pelanggan dan $(U) \times$ pelanggan pada section 1 yaitu sebesar 700,449596 dan 1140,099265 . Hal yang sama juga dilakukan pada section yang lainnya dan didapatkan hasil seperti tabel 3.

Tabel 3. Nilai Keandalan Penyulang Blahkiuh

\begin{tabular}{cccc}
\hline \multirow{2}{*}{ Section } & \multirow{2}{*}{$\begin{array}{c}\text { Jumlah } \\
\text { Pelanggan }\end{array}$} & \multicolumn{2}{c}{ Repair time $(\boldsymbol{r})$} \\
\cline { 3 - 4 } & & $\begin{array}{c}\boldsymbol{\lambda} \mathbf{x} \\
\text { Pelanggan }\end{array}$ & $\begin{array}{c}\mathbf{U} \mathbf{x} \\
\text { Pelanggan }\end{array}$ \\
\hline 1 & 3439 & 700,449596 & 1140,099265 \\
\hline 2 & 2153 & 917,211169 & 1657,147277 \\
\hline 3 & 3210 & 3011,798726 & 2805,60676 \\
\hline 4 & 868 & 3922,177 & 3646,776772 \\
\hline 5 & 1375 & 1564,15867 & 1596,201955 \\
\hline Total & 11045 & 10115,79516 & 10845,83203 \\
\hline
\end{tabular}

Untuk mendapatkan nilai indeks keandalan pada penyulang Blahkiuh yaitu berupa nilai SAIDI dan SAIFI maka dapat dihitung dengan cara membagi nilai total dari laju kegagalan dengan jumlah pelanggan penyulang Blahkiuh serta membagi nilai total ketidaktersediaan dengan jumlah pelanggan penyulang Blahkiuh sesuai dengan pada persamaan (1) dan (2) yang dapat dijabarkan sebagai berikut: 


$$
\begin{aligned}
\text { SAIDI } & =\frac{\sum \mathrm{U}_{\mathrm{i}} \cdot \mathrm{N}_{\mathrm{i}}}{\sum \mathrm{N}_{\mathrm{i}}} \\
& =\frac{10845,83203}{11045} \\
& =0,981 \mathrm{jam} / \text { pelanggan } / \text { tahun } \\
\text { SAIFI } & =\frac{\sum \lambda_{\mathrm{i}} \cdot \mathrm{N}_{\mathrm{i}}}{\sum \mathrm{N}_{\mathrm{i}}} \\
& =\frac{10115,79516}{11045} \\
& =0,915 \mathrm{kali} / \text { pelanggan/tahun }
\end{aligned}
$$

\subsection{Proses Algoritma Genetika}

Pengoptimasian algoritma genetika dapat dilakukan menggunakan software komputasi numerikal yang biasa disebut MATLAB atau Matrix Laboratory. Ada beberapa tahapan yang perlu dilakukan dalam proses mereposisi recloser saluran menggunakan algoritma genetika yaitu inisialisasi populasi, decode kromosom, evaluasi individu, linier fitness ranking, roulette wheel, crossover dan mutasi.

Dalam menentukan letak reposisi recloser, penulis mengasumsikan recloser dapat direposisi berdasarkan dari letak load point yang ada dalam penyulang Blahkiuh. Maka input yang digunakan sebagai gen awal dalam proses algoritma genetika yaitu jumlah dan nilai load point penyulang Blahkiuh. Hasil reposisi recloser saluran seperti tabel 4 yang didapat dari penggabungan tujuh tahapan algoritma yaitu, Inisialisasi Populasi, Dekode Kromosom, Evaluasi Individu, Linear Fitness Ranking (LFR), Roulette Wheel Selection, Pindah Silang (Crossover), dan Mutasi.

Tabel 4. Hasil Proses Algoritma Genetika

\begin{tabular}{cccccccc}
\hline No & Fitness & \multicolumn{3}{c}{ Posisi } & & SAIDI & SAIFI \\
\hline 1 & 0,5604 & 21 & 11 & 75 & 48 & 0,9199 & 0,8645 \\
\hline 2 & 0,5602 & 86 & 48 & 75 & 21 & 0,9205 & 0,8645 \\
\hline 3 & 0,5604 & 11 & 78 & 21 & 48 & 0,9198 & 0,8645 \\
\hline 4 & 0,5602 & 77 & 43 & 48 & 80 & 0,9207 & 0,8645 \\
\hline 5 & 0,5601 & 78 & 86 & 77 & 11 & 0,9208 & 0,8646 \\
\hline
\end{tabular}

\subsection{Analisis Hasil Perbandingan}

Berdasarkan optimasi menggunakan metode algoritma genetika didapatkan hasil indeks keandalan penyulang Blahkiuh yaitu
SAIDI 0,919 jam/pelanggan/tahun dan SAIFI 0,864 kali/pelanggan/tahun. Persentase perbandingan dari kedua hasil tersebut dapat dijabarkan sebagai berikut:

$$
\begin{aligned}
\text { Persentase SAIFI } & =\frac{16,534-0,864}{16,534} \times 100 \% \\
& =(+) 94 \% \\
\text { Persentase SAIDI } & =\frac{35,894-0,919}{35,894} \times 100 \% \\
& =(+) 97 \%
\end{aligned}
$$

Jika dibandingkan terdapat peningkatan nilai SAIFI sebesar 94\% dan peningkatan nilai SAIDI sebesar 97\%, Jadi dengan menggunakan metode algoritma genetika didapatkan hasil indeks keandalan SAIDI dan SAIFI yang sudah memenuhi standar WCS dan WCC seperti pada tabel 5 dan gambar 2 .

Tabel 5. Perbandingan Hasil Keandalan

\begin{tabular}{ccc}
\hline $\begin{array}{c}\text { Indeks } \\
\text { Keandalan }\end{array}$ & $\begin{array}{c}\text { SAIDI } \\
\text { (jam/pelanggan/ } \\
\text { tahun) }\end{array}$ & $\begin{array}{c}\text { SAIFI } \\
\text { (kali/pelanggan/ } \\
\text { tahun) }\end{array}$ \\
\hline Penelitian [1] & 35,894 & 16,534 \\
\hline $\begin{array}{c}\text { Algoritma } \\
\text { Genetika }\end{array}$ & 0,919 & 0,864 \\
\hline
\end{tabular}

Perbandingan Hasil Keandalan

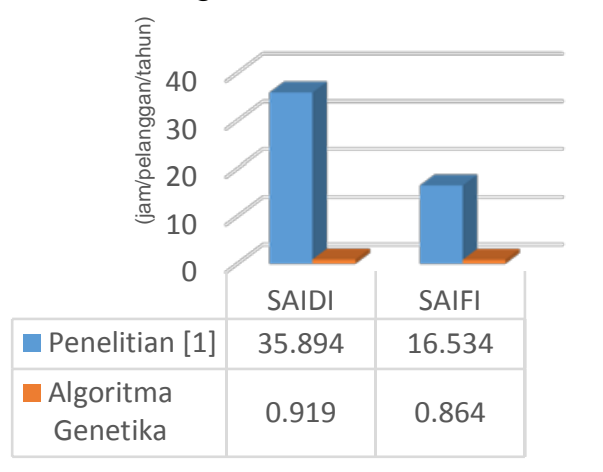

Gambar 2 Perbandingan Hasil Keandalan

\section{KESIMPULAN}

Berdasarkan hasil dari pembahasan mengenai reposisi recloser saluran menggunakan metode algoritma genetika pada penyulang Blahkiuh dapat disimpulkan sebagai berikut:

1. Dengan menggunakan metode algoritma genetika didapatkan letak recloser yang paling optimal yaitu 
berada di load point 11, 21, 48, 78 dengan nilai fitness mencapai 0.5604 serta nilai SAIDI 0,9198 jam/pelanggan/tahun dan SAIFI 0,8645 kali/pelanggan/tahun.

2. Dengan menggunakan metode algoritma genetika didapatkan hasil indeks keandalan SAIDI dan SAIFI yang sudah memenuhi standar WCS (World Customer Service) dan (World Class Company).

\section{DAFTAR PUSTAKA}

[1] Bagus, W. Y. 2016. Studi Pengaruh Pemasangan Loop Scheme Terhadap Keandalan Penyulang Blahkiuh Dan Penyulang Panglan Ditinjau Dari Aspek Ekonomi. Jimbaran: Universitas Udayana.

[2] Indra, S.R. dan Sukma, D. Y. 2016. Kajian Penempatan Recloser pada Jaringan Distribusi Menggunakan Metode Algoritma Genetika Berdasarkan Keandalan Maksimum. Pekanbaru: Universitas Riau.

[3] Gunantara, N., \& Dharma, A. 2017 Optimal Path Pair Routes Through
Multi-Criteria Weight In Ad Hoc Network Using Genetic Algorithm. International Journal of Communication Network And Information Security (IJCNIS).

[4] Chowdhury, A. dan Koval, D. 2009. Power Distribution System Reliability Practical Methods and Applications. New Jersey : IEEE Press.

[5] PT. PLN (Persero). Keandalan Pada Sistem Distribusi 20kV dan 6kV. Jakarta : SPLN No.59 : 1985

[6] Zukhri, Z. 2013. Algoritma Genetika Metode Komputasi Evolusioner untuk Menyelesaikan Masalah Optimasi. Yogyakarta: Andi.

[7] Radiktyo, N. S. 2011. Optimasi Penempatan Recloser Terhadap Keandalan Sistem Tenaga Listrik dengan Algoritma Genetika. Semarang : Universitas Diponegoro.

[8] Rukmi, S. H. dan Sukerayasa. 2010. Penerapan Metode Pendekatan Teknik Untuk Meningkatkan Keandalan Sistem Distribusi. Jimbaran: Universitas Udayana. 